\title{
MISI DAN SPIRIT WESLEYAN: MENUJU MANUSIA INDONESIA UNGGUL
}

\author{
The Paw Liang \\ Sekolah Tinggi Teologi Wesley Methodist Indonesia \\ pawliang@gmail.com
}

\begin{abstract}
The Indonesian Government is currently championing human capital as the top priority program of the Indonesia Maju Cabinet (Cabinet Indonesia Onward). Human Capital 0.53 and Global Competitieness Index 50/141 indicate the inferior quality and the sustainability of the nation. This article applies three three factors in reading the maping the reality and challenges for Indonesia: Industrial Revolution 4.0, Globalisation and Generational Changes, and Demographic Bonus. How could the church participate in this nation building? John Wesley applied a holistic approach in facing similar situation in the $18^{\text {th }}$ Century England. Learning from the Methodist movement, this article try to suggest few possible solutions for churches in Indonesia, especially the Wesleyans.
\end{abstract}

Keywords: Human Resources; Excellent; Wesleyan; Human Capital; Spirit; Holiness; movement; biblical; Christian Perfection;

\begin{abstract}
ABSTRAK
Pemerintah Indonesia mencanangkan pembangunan SDM Unggul sebagai program kerja Kabinet Indonesia Maju. Human Capital 0,53 dan Global Competitiveness Index 50/141-yang rendah memberikan indikator kemampuan bertahan bangsa Indonesia di panggung dunia. Artikel ini memakai tiga faktor dalam memeta realita dan tantangan bagi Indonesia: Revolusi Industri Jilid 4 dan Globalisasi, Pergeseran Budaya Generasi, dan Bonus Demografi. Bagaimana gereja-gereja dapat turut berperan-serta dalam pembangunan manusia Indonesia yang seutuhnya. Tulisan ini menelusuri respon John Wesley terhadap kelesuan iman, kehidupan ekonomi dan sosial politik di Inggris pada abad 18 untuk dapat menjadi pembelajaran gereja di Indonesia dalam menghadapi tantangan yang tidak jauh berbeda. Misi dan spirit Wesleyan (kegerakan Methodist) memperhatikan seluruh aspek kehidupan-membangun iman dan kapasitas para anggota melalui pertemuan-pertemuan Methodist (Society, Class Meeting, Band) dan dalam seluruh aspek kehidupan bermasyarakat.
\end{abstract}

Kata Kunci: SDM; Unggul; Wesleyan; Human Capital; spirit; misi; kekudusan; kegerakan; Alkitabiah; kesempurnaan; Kristen;

\section{PENDAHULUAN: MENUJU SDM INDONESIA UNGGUL}

Pemerintah di bawah pimpinan Presiden Joko Widodo mencanangkan tema peringatan Hari Kemerdekaan Republik Indonesia 2019: "Menuju Indonesia Unggul" dengan penekanan pada pembangunan sumber daya manusia (SDM). Prioritas ini tampak pada APBN 2020. Pemerintah mengalokasikan $20 \%$ dari dana APBN untuk pendidikan atau 505,8 triliun; dan kesehatan 5\% atau Rp 132,2 triliun. Tidak cukup hanya membangun kompetensi dan kapabilitas, Presiden juga menekankan pembangunan "SDM yang berbudi pekerti luhur dan berkarakter kuat. ... berakar pada budaya bangsa memperjuangkan kepentingan nasional dan tanggap terhadap perubahan dunia. ${ }^{i}$ 
Kerohanian yang sehat akan membentuk insan-insan yang sehat dan berdampak bagi kehidupan berbangsa. Kehadiran gereja adalah untuk menjadi garam dan terang. Abad 18, perkembangan ilmu pengetahuan dan teknologi memunculkan industri-industri baru di Eropa dan mempengaruhi tantanan kehidupan di masyarakat, khususnya kesenjangan ekonomi. John Wesley meresponi realita ini dengan membantu para pengikutnya yang sebagian besar dari kalangan miskin, mendisiplinkan diri untuk hidup kudus melalui Society, Class, dan Band Meeting. Banyak ahli sejarah yang mengakui kegerakan Methodist telah membantu Inggris bebas dari revolusi industri. ${ }^{i i}$ Bagaimana misi dan pengaruh Wesleyan dapat menjadi model bagi gereja dalam menjawab tantangan dan pergumulan bangsa Indonesia saat ini.

\section{GAMBARAN SDM INDONESIA DI TAHUN 2019}

Bank Dunia melaporkan bahwa Human Capital Index Indonesia hanya 0,53-artinya seorang tenaga kerja Indonesia pada generasi berikut hanya memiliki tingkat produktivitas sebesar $53 \%$ dibandingkan jika ia memiliki pendidikan dan kesehatan yang memadai. Saat ini secara rata-rata anak-anak Indonesia memiliki peluang mengecam pendidikan selama 12.3 tahun sampai ia berumur 18 tahun. Namun karena kualitas pendidikan yang rendah, anak-anak Indonesia secara rata-rata hanya mendapatkan 7,9 tahun pendidikan yang bermutu. Dari segi kesehatan, sepertiga anak-anak Indonesia mengalami kuntet, yang memberikan resiko keterbatasan fisik dan kemampuan kognitif yang berdampak sepanjang hidup mereka. ${ }^{\text {iii }}$

Forum Ekonomi Dunia 2019 menempatkan Indonesia pada urutan ke-50 dari 141 negara pada Global Competitiveness Index. Penilaian daya saing ini berfokus pada kemampuan untuk bertumbuh secara jangka panjang dengan memakai 103 indikator yang dikelompokkan menjadi 12 tema. Keduabelas tema indikator ini adalah: institusi, infrastruktur, pemakaian Internet Communication Technology, stabilitas makroekonomi, kesehatan, ketrampilan, pasar produk, pasar tenaga kerja, sistem finansial, ukuran pasar, dinamika bisnis, dan kapabilitas inovasi. ${ }^{\text {iv }}$

Pada Periode tahun 2030 hingga 2040 Indonesia akan memasuki bonus demografi dengan jumlah usia produktif (15-64 tahun) sebesar 64\% dari seluruh populasi yang diprediksikan mencapai 297 juta jiwa. Bonus demografi dengan angkatan kerja yang besar sangat menentukan tingkat kesejahteraan bangsa. Bagaimana meningkatkan kapasitas angkatan tenaga kerja? Saat ini, dari 131,5 juta angkatan kerja, sekitar 63 persen merupakan lulusan sekolah menengah pertama atau lebih rendah. Kedua, pendidikan dan keterampilan yang dimiliki tenaga kerja tidak sesuai dengan kebutuhan industri sehingga menyebabkan industri mengalami kesulitan untuk mendapatkan tenaga kerja yang berkualitas. ${ }^{\mathrm{v}}$

Melihat fenomena sumber daya manusia Indonesia, wajar jika pemerintah memberikan perhatian khusus untuk pembangunan Human Capital. Arus globalisasi membuat persaingan semakin tajam dan perang dagang semakin memanas. Antar-negara berebut investasi, antar-negara berebut teknologi, berebut pasar, dan berebut orang-orang pintar. Antar-negara memperebutkan talenta-talenta hebat yang bisa membawa kemajuan bagi negaranya. Bagaimana Gereja meresponi, realita ini?

Berikut ini faktor eksternal yang mempengaruhi pembangunan SDM antara lain: 


\section{TANTANGAN REVOLUSI INDUSTRI JILID 4 DAN GLOBALISASI}

Revolusi Industri Jilid 4 yang dikenal dengan Internet of Things (IoT) dan otomatisasi mempercepat laju perubahan dan menimbulkan disrupsi yang sangat besar. Disrupsi ini jauh melampaui tiga revolusi industri terdahulu. Otomatisasi dan kecerdasan buatan (artificial intelligent) menggantikan tenaga manusia bukan hanya tenaga kerja di perbankan dan kegiatan jual beli online, eMoney, taxi online. Kecerdasan buatan ditopang dengan teknologi digital bahkan mampu melakukan tindakan medis dari jarak jaruh. Rhenald Kasali

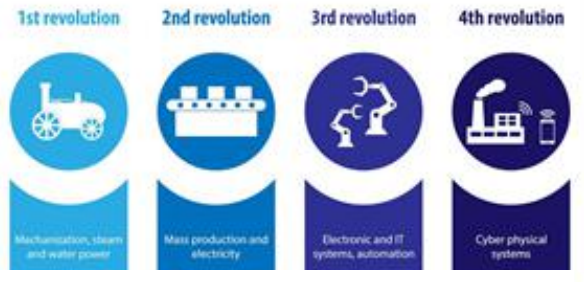

Gambar 1. Revolusi Industri dalam bukunya, "Disruption" banyak memberikan contoh-contoh aspek-aspek kehidupan yang diubah oleh budaya IoT. ${ }^{\text {vi }}$

Globalisasi dan Revolusi Industri 4.0 menciptakan banyak kesempatan sekaligus menimbulkan disrupsi dan polarisasi dalam kehidupan ekonomi dan tantan masyarakat. Perubahan yang cepat dan luas ini mengubah sistem-sistem produksi, managemen, dan pemerintahan serta mengubah cara kita bekerja, hidup, ibadah bahkan mengekspresikan identitas kita. Perubahan ini cepat dan bisa terjadi kapan saja, sulit diprediksi sehingga menimbulkan disrupsi. Kecerdasan buatan (Artificial Intelligence, AI) sudah banyak menggantikan pekerjaan, jual beli secara fisik menjadi transaksi online.

Kemudahan arus komunikasi dan interaksi juga membawa ancaman: ancaman terhadap ideologi negara, ancaman terhadap nilai-nilai, tradisi dan seni budaya kita, serta ancaman terhadap warisan kearifan-kearifan lokal bangsa Indonesia. ${ }^{\text {vii }}$ The Pew Research Centre menunjukkan bahwa selain meningkatnya tingkat konektivitias, religiositas dunia mengalami peningkatan. Untuk itu kita perlu melihat kembali nilai-nilai agama, cara pandang (worldview) dan perilaku serta relasi antara sesame manusia. viii

Perubahan ini membuat masyarakat semakin memerlukan inspirasi dan pegangan dari nilai-nilai agama dan warisan budaya mereka. Masyarakat memerlukan pengajaran dan sentuhan iman yang memberikan pemahaman nilai-nilai hidup, membentuk cara-pandang dunia (worldview), serta untuk menentukan perilaku dan cara berelasi dan berinteraksi.

Arus globalisasi di Indonesia dapat dilihat dari semakin meningkatnya pengguna jasa internet. Hasil studi Polling Indonesia yang bekerja sama dengan Asosiasi Penyelenggara Jasa Internet Indonesia ( APJII) tahun 2017, jumlah pengguna internet di Indonesia adalah 143,26 jiwa atau sekitar 54,68\% dari 262 juta jiwa. Tahun 2018, bertumbuh menjadi mencapai 171,17 jiwa atau sekitar 64,8 persen dari 264 juta jiwa. ${ }^{\text {ix }}$ Menempatkan Indonesia sebagai pengguna internet terbanyak ke- 6 di dunia. 
Dari sisi umur, pegguna internet terbesar dapat diurutkan sebagai berikut:

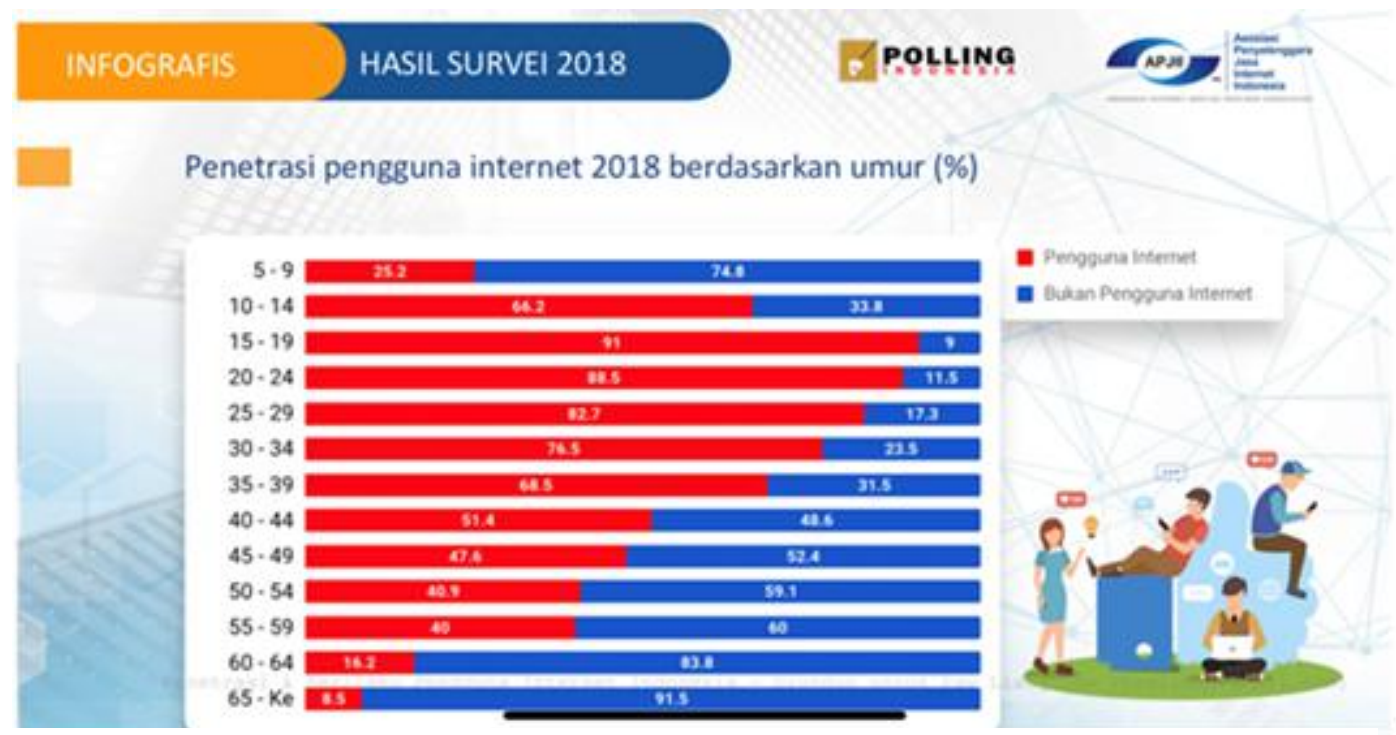

Gambar 2. Penetrasi Pengguna Internet 2018 Berdasarkan Umur

1. Kelompok umur 15 sampai 19 tahun sebesar $91 \%$

2. Kelompok umur adalah 20 sampai 24 tahun sebesar $88,5 \%$

3. Kelompok umur 25 sampai 29 tahun sebesar $82,7 \%$

4. Kelompok umur 30 sampai 34 tahun sebesar 76,5\%

5. Kelompok usia umur 35 sampai 39 tahun sebesar $68,5 \%$,

6. Kelompok umur 10 sampai 14 tahun sebesar $66,2 \%$

Rata-rata pengguna internet Generasi Millenial dan i-Generasi di atas 65\% membuat kedua generasi ini memiliki lebih banyak kesamaan dengan anak muda seusia mereka yang menjadi "digital native" (penduduk asli dunia digital).

Berdasarkan alasan menggunakan internet paling banyak untuk komunikasi lewat pesan $(24,7 \%)$, sosial media (18,9\%) mencari informasi terkait pekerjaan $\quad(11,5 \%)$, mencari data untuk sekolah/kuliah (9.6\%). Alasan kedua dalam menggunakan internet paling tinggi untuk sosial media (19,1\%), komunikasi lewat pesan (16,4\%), dan mengisi waktu luang (15,2\%). Namun data tidak dipecah berdasarkan kelompok umur. Data in menunjukkan pergeseran interaksi antar manusia yang semakin bergeser dari fisik ke digital. 


\section{GLOBALISASI: LOMPATAN DARI BUDAYA RURAL MENJADI BUDAYA GLOBAL?}

Keterbukaan dan konektivitas membuat perjumpaan lintas budaya tidak terhindarkan. Perjumpaan ini bisa memperkaya tapi juga bisa membingungkan bahkan mengacaukan hidup. Ahli antropolgi sebelumnya menggolongkan manusia dalam "Budaya Penduduk Terpencil (sering disebut primitif, Tribal Culture), Budaya Desa (Village culture), Budaya Kota (Urban Culture), dam Budaya Global.

Budaya Penduduk Terpencil, contoh suku Badui di Banten, suku Anak Dalam di Jambi, yang tertutup dari pengaruh budaya luar. Budaya Desa secara umum didominasi oleh suku tertentu dan kadang ada pendatang yang datang dari tempat lain atau suku lain. Desa umumnya bersifat lebih terbuka untuk pendatang dan sudah berinteraksi dengan kota atau pun dunia luar. Budaya Urban lebih majemuk dengan penduduk yang datang dari berbagai kota, bahkan pulau di Indonesia. Di beberapa kota juga terdapat komunitas dari mancanegara.

Survei yang dilakukan oleh APJII menunjukkan bahwa pengguna internet di daerah rural sudah mencapai 61,6\%. Pemakaian internet di kota-kota di Indonesia pada tahun 2018, sudah mencapai 74,1\%. Data ini memberikan indikasi keterbukaan daerah pedesaan dan urban terhadap budaya digital, Internet of Things.

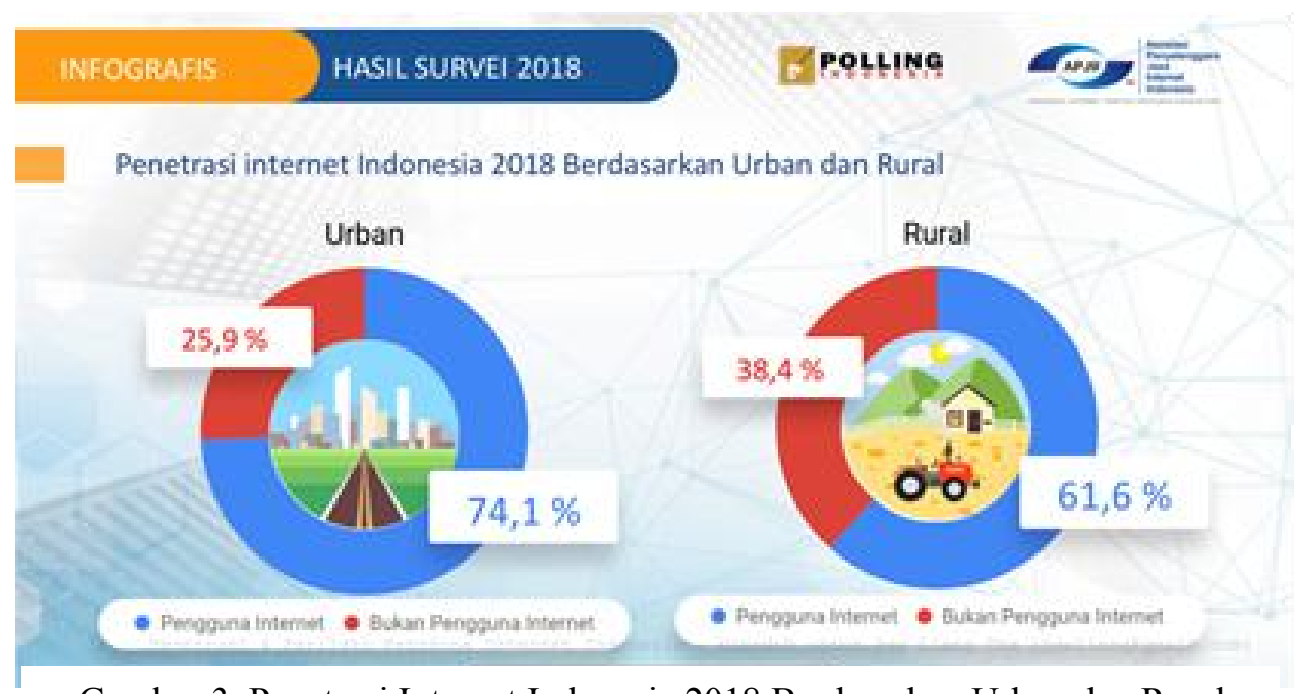

Gambar 3. Penetrasi Internet Indonesia 2018 Berdasarkan Urban dan Rural

Revolusi Industri Jilid 4 yang mempercepat derap komunikasi juga diwarnai dengan tingkat mobilitas yang sangat tinggi baik untuk pekerjaan, studi, maupun berlibur. Internet of Things memberi kesempatan untuk berinteraksi kepada masyarakat global tanpa dirintangi oleh jarak geografis. Interaksi dan arus informasi digital menjadi salah satu faktor penentu dalam membentuk cara pandang masyarakat saat ini.

\section{TANTANGAN BUDAYA GENERASI \& KECERDASAN GENERASIONAL}

Secara umum budaya generasi didefinisikan sebagai sekelompok orang yang lahir dan masa mudanya dibentuk oleh serangkaian peristiwa, tren serta pembuat opini publik. Pengalaman bersama ini membuat 
setiap generasi secara tidak sadar mengembangkan nilai-nilai dan cara pandang (worldview) terhadap kehidupan. ${ }^{x}$

Sulit untuk ditelusuri siapa yang memberikan nama dan definisi budaya generasi ini. Lebih tepat mungkin kesepakatan bersama atau kolaborasi (crowdsourcing) yang menjadi karakteristik era globalisasi ini. ${ }^{\mathrm{xi}}$ Secara umum, pembagian generasi dikelompokkan menjadi: Tradisionalis (Generasi Pembangun yang lahir sebelum tahun 1945), Baby Boomers (lahir tahun 1946 - 1965), Generation X (lahir tahun 1966 - 1977), Millenial (lahir tahun 1978 - 1995), dan iGen / Gen Z (lahir setelah 1995).

\begin{tabular}{|c|c|c|c|c|}
\hline $\begin{array}{l}\text { TRADISIONALIST } \\
\text { Pra-1945 }\end{array}$ & $\begin{array}{l}\text { BOOMERS } \\
1946-1965\end{array}$ & $\begin{array}{l}\text { GEN X } \\
1966-1977\end{array}$ & $\begin{array}{l}\text { MILLENIAL } \\
1978-1995\end{array}$ & $\begin{array}{l}\text { i-GEN } \\
\text { Setelah } 1995\end{array}$ \\
\hline $\begin{array}{l}\text { Pengalaman } \\
\text { Depresi Besar, PD I\&II }\end{array}$ & $\begin{array}{l}\text { Pengalaman: } \\
\text { TV, Mendarat di } \\
\text { bulan, Watergate, } \\
\text { Perang Vietnam. }\end{array}$ & $\begin{array}{l}\text { Pengalaman: } \\
\text { MTV, Nintendo, } \\
\text { Komputer (PC) }\end{array}$ & $\begin{array}{l}\text { Pengalaman: } \\
\text { Bencana alam, } \\
\text { keragaman, } \\
\text { teknologi seluler }\end{array}$ & $\begin{array}{l}\text { Pengalaman: } \\
\text { Resesi ekonomi, } \\
\text { Pemanasan } \\
\text { Global }\end{array}$ \\
\hline $\begin{array}{l}\text { Makna Pekerjaan: } \\
\text { Obligasi / wajib }\end{array}$ & $\begin{array}{l}\text { Makna } \\
\text { Pekerjaan: } \\
\text { Diharapkan }\end{array}$ & $\begin{array}{l}\text { Makna } \\
\text { Pekerjaan: } \\
\text { Tantangan }\end{array}$ & $\begin{array}{l}\text { Makna } \\
\text { Pekerjaan: } \\
\text { Jalan untuk } \\
\text { mencapai tujuan }\end{array}$ & $\begin{array}{l}\text { Makna } \\
\text { Pekerjaan: } \\
\text { Terus berevolusi }\end{array}$ \\
\hline $\begin{array}{l}\text { Aspirasi: } \\
\text { Memiliki rumah }\end{array}$ & $\begin{array}{l}\text { Aspirasi: } \\
\text { Pekerjaan tetap }\end{array}$ & $\begin{array}{l}\text { Aspirasi: } \\
\text { Hidup-kerja } \\
\text { seimbang, } \\
\text { Mandiri }\end{array}$ & $\begin{array}{l}\text { Aspirasi: } \\
\text { Bebas dan fleksibel }\end{array}$ & $\begin{array}{l}\text { Aspirasi: } \\
\text { Terstruktur dan } \\
\text { stabil }\end{array}$ \\
\hline $\begin{array}{l}\text { Jalur Karir: } \\
\text { Perlahan tapi pasti }\end{array}$ & $\begin{array}{l}\text { Jalur Karir: } \\
\text { Terus menanjak }\end{array}$ & $\begin{array}{l}\text { Jalur Karir: } \\
\text { Perlu ada opsi } \\
\text { lain saat ini }\end{array}$ & $\begin{array}{l}\text { Jalur Karir: } \\
\text { Cepat dan sering } \\
\text { berganti }\end{array}$ & $\begin{array}{l}\text { Jalur Karir: } \\
\text { Karir } \\
\text { "multi-taskers" }\end{array}$ \\
\hline
\end{tabular}

Tabel 1. Budaya Generasi

\section{Generasi Pembangun / Tradisionalis (lahir sebelum 1945)}

Generasi ini lahir pada masa Depresi ekonomi dunia dan sekitar Perang Dunia II. Kesulitan ekonomi di masa kecil membentuk mereka menjadi disiplin dan rela berkorban. Mereka biasanya setia pada organisasi dan memiliki semangat tim kerja yang baik, membangun legasi dan etika kerja yang baik. Sebagian besar sudah pensiun tetapi masih memiliki pengaruh dalam kehidupan organisasi melalui peraturan dan legasi yang mereka tinggalkan.

\section{Baby Boomers (lahir antara tahun 1946 dan 1965)}

Generasi ini bertumbuh dengan penuh pengharapan setelah perang dunia. Biasanya dibesarkan dalam keluarga inti, dengan ibu rumah tangga. Dalam konteks budaya Indonesia yang komunal masih banyak yang bertumbuh dalam keluarga besar. Boomers adalah pekerja ulet, optimis dan driven (mengendalikan situasi). Mereka selalu berusaha untuk sukses, cakap dalam mengatasi masalah dan menemukan solusi. Jumlah populasi generasi ini cukup besar, sehingga masih banyak yang mendominasi dunia kerja sampai saat ini.

\section{Generation X (lahir antara tahun 1966 dan 1977)}

Generasi ini mulai mengenal perceraian dan ibu yang bekerja sehingga banyak Generasi $\mathrm{X}$ yang cenderung mandiri, resilient (anjal, tahan menghadapi masalah), dan fleksibel. Dalam konteks Indonesia, perceraian dan ibu yang bekerja mungkin baru muncul di pertengahan tahun 70an. Generasi ini bertumbuh pada masa resesi ekonomi, begitu selesai kuliah sulit mendapatkan pekerjaan. Sehingga 
membuat generasi ini tidak terpaku pada satu organisasi dan terbuka untuk mengejar kesempatan karir yang lebih baik. Mulai terjadi degrasi dalam hal respek terhadap otoritas dan mengharapkan perlakukan yang lebih egaliter, fleksibel dan ruang untuk partisipasi. Sifat mandiri membuat generasi ini lebih memperhatikan keseimbangan dalam hidup, lebih menitikberatkan nilai-nilai dan target-target pribadi daripada target-target yang berkaitan dengan kerja.

\section{Millennials (lahir antara tahun 1978 dan 1995)}

Dibesarkan dalam dunia yang berfokus pada anak, generasi ini mendapatkan perhatian yang berlebihan dari orang dewasa. Hal ini membuat mereka menjadi penuh percaya diri, optimis dan berfokus pada pencapaian. Mereka juga terlahir dalam budaya teknologi sehingga dibandingkan generasi sebelumnya, Millenial lebih fasih dalam menggunakan teknologi. Orangtua melibatkan mereka dalam berbagai aktivitias sekolah, olah raga dan sosial membuat mereka menjadi multi-tasking.

\section{i-Gen atau Gen Z (lahir setelah 1995)}

I-Gen atau Generasi Z sangat terkoneksi dengan internet dan terobsesi dengan gaming. Generasi internet ini adalah generasi pertama yang menghabiskan seluruh masa remaja mereka di era ponsel pintar (smartphone). Mereka menyerap informasi secara visual seperti infografis dan video. Budaya internet membuat mereka menjadi mandiri, multitasking, dan fasih dengan budaya otomatisasi bahkan tidak sedikit yang mulai mendapatkan penghasilan melalui dunia digital di usia remaja. Mereka menghabiskan sebagian besar waktu di media sosial dan texting, dan tidak banyak interaksi secara fisik. Hal ini dicurigai menimbulkan tingginya tingkat kecemasan, depresi dan kesepian. Lahir dan bertumbuh di era Pemanasan Global dan kepedulian lingkungan membuat generasi ini lebih peduli terhadap lingkungan dan memiliki cara-pandang yang lebih terbuka terhadap agama, seksualitas, dan politik. Kedewasaan mereka juga berkembang lebih lambat dari generasi-generasi sebelumnya: umur delapanbelas masih terlihat seperti umur limabelas. Pola pikir remaja berlanjut hingga umur duapuluhan. ${ }^{\text {xii }}$

Pengelompokan katerakteristik budaya generasi ini sebagian besar dilakukan oleh para ahli khususnya para psikolog sosial dan perilaku dari negara Barat. Belum ada survey atau pengamatan terhadap budaya generasi di Indonesia yang dipublikasikan. Pemaparan karakteristik budaya generasi di atas merupakan garis besar, sejauh mana budaya tersebut mempengaruhi seseorang tergantung sejauh mana seseorang itu berinteraksi dengan dunia luar: tribal (terpencil), rural, urban, atau global, termasuk sejauh mana pengaruh teknologi dan internet dalam kehidupannya sehari-hari.

Di tengah-tengah arus perubahan dan disrupsi ini, kita perlu melihat kembali eksistensi dan panggilan kita sebagai gereja. Pertama, memetakan kembali: budaya apa yang mempengaruhi hidup saya, keluarga, gereja, dan masyarakat? Kedua, menganalisa dan memilah aspek dan nilai-nilai apa yang harus berubah, apa yang harus disesuaikan, dan apa yang tidak boleh berubah. Gereja dipanggil bukan untuk menjadi serupa dengan dunia ini. Tetapi diutus untuk menjadi garam dan terang (Matius 5:13-16), menjadi nurani di masyarakat dengan suara nabiah, dan ikut berperan dan terlibat dalam membentuk budaya generasi. Konteks misi dan pelayanan (form) akan senantiasa berubah, tetapi muatan (iman) gereja harus berakar kuat dalam Alkitab.

Bertitik tolak dari pertanyaan di atas, pemaparan berikut menelurusi sejarah, teologi misi Wesleyan untuk menarik beberapa prinsip yang Wesley yang dapat diterapkan gereja dalam menjawab tantangan masa ini. 


\title{
5. MISI DAN SPIRIT WESLEYAN UNTUK MENUJU SDM INDONESIA UNGGUL
}

\author{
"There is no religion but social religion, no holiness but social holiness"
}

John Wesley memberikan perhatian yang besar untuk pendidikan untuk mereformasi gereja dan bangsa Inggris. Kegerakan Methodist dan kontribusi Wesley terhadap negara Inggris, khususnya dalam pembangunan SDM sangat dipengaruhi teologinya khususnya tentang gambar Allah, anugerah dan pemulihan untuk mencapai kesempurnaan Kristen.

\section{Kegerakan Methodist dan Class Meeting: Membangun Iman dan Kapasitas}

Kegerakan Methodist dimulai sebagai respon John Wesley melihat kelesuan rohani dan ketidakberdayaan kaum miskin dan marjinal di Inggris pada abad 18. Pada masa itu, gereja hanya dipenuhi oleh kaum elit yang kaya dan terpelajar. Seperti negara Eropa lainnya, era Pencerahan (Enlightenment) juga memunculkan kaum skeptis dan atheis di Inggris, serta degrasi dalam kehidupan moral dan inflasi yang membuat kaum miskin semakin tidak berdaya. John Wesley tidak pernah berniat mendirikan gereja baru, tetapi ingin mereformasi Gereja Anglikan dari dalam.

Untuk menjangkau kaum miskin di luar gereja, Wesley berkhotbah di luar gereja; di tempat-tempat umum, pasar-pasar, kepada buruh pabrik, petani dan para buruh tambang. Melalui khotbah dan pengajarannya banyak orang yang mengalami lahir baru. Dibantu oleh beberapa pendeta Anglikan dan kaum terpelajar yang mendukungnya dan sebagian kemudian menjadi pengkhotbah Awam, John Wesley mengorganisir para pengikutnya yang disebut orang-orang Methodist ke dalam Society (paguyuban), Class (Kelas) yang terdiri dari 10 - 12 orang dan Band berdasarkan gender (untuk 4-5 orang). Orang-orang Methodist masih mengikuti ibadah dan Perjamuan Kudus di Gereja Anglikan, tetapi mereka bertemu secara rutin untuk berbibadah bersama dan mendengarkan pengajaran dari John Wesley atau para pengkhotbah awam yang lain melalui Society-society Methodist. Wesley mengumpulkan par pengkhotbah awam ini secara rutin yang disebut Konferensi, untuk membimbing dan memperlengkapi mereka.

Tahun 1739, dibangunlah gedung pertemuan yang pertama yang diberi nama New Room untuk pertemuan Paguyuban Methodist ini. New Room dibangun dengan memakai dana pinjaman dari bank. Untuk pengumpulan dana, orang-orang Methodist dibagi menjadi kelompok-kelompok kecil $10-12$ orang yang disebut Kelas (Class). Setiap kelompok memiliki satu orang Pemimpin. Seminggu sekali mereka berkumpul (Class Meeting) untuk mengumpulkan dana. Inilah tujuan awal pembentukan Class.

John Wesley sangat menekankan pertumbuhan kerohanian / kekudusan menuju "Kesempurnaan Kristen" (Christian Perfection) atau kadang dalam tulisannya disebut juga "Kesempurnaan Kasih" (Perfect Love). Pertumbuhan dimulai ketika kita menerima Anugerah Keselamatan melalui Yesus Kristus. Perjumpaan dengan Kristus membuat kita melihat keberdosaan kita dan menyadari gambar Allah (imago Dei) yang telah rusak dalam diri kita. Anugerah Keselamatan membuka pintu bagi kita untuk dipulihkan dan bertumbuh menuju gambar Allah yang seutuhnya yang sering disebut Wesley dengan Kesempurnaan. Wesley mengajarkan orang-orang Methodist untuk terus mengejar kekudusan hidup dengan mengandalkan anugerah pengudusan (sanctifying grace), anugerah yang mengubah hidup kita (transforming grace) untuk menjadi serupa dengan Kristus dalam Kesempurnaan Kristen (Roma 8:29, Efesus 4:13).

Ketika mengunjungi para anggota, pemimpin-pemimpin Kelas menemukan para anggota masih bergumul untuk bertumbuh dalam kekudusan. Banyak yang masih tidak mampu meninggalkan kebiasaan lama; mabuk-mabukan, berjudi, berkelahi, berutang, kekerasan rumah tanggal, dan kebiasan buruk lainnya. Mendengar lapporan ini, John Wesley mengubah Class Meeting, bukan lagi sekedar mengumpulkan dana tetapi juga untuk menjadi sarana dalam pertumbuhan rohani dan pengenalan akan 
Tuhan. John Wesley kemudian menerapkan disiplin yang ketat untuk orang-orang Methodist dengan Tiga Peraturan yang sederhana (Three Simple Rules) ${ }^{\mathrm{xiii}}$ :

1. Do no harm, and avoid evil in every kind (tidak melakukan hal-hal yang jahat/merugikan).

2. Do good of every possible sort, and as far as possible to all men. (Lakukan kebaikan dalam segala bentuk dengan sedaya mungkin kepada semua orang.)

3. Attend upon all the ordinances of God (Menjalankan ketetapan Tuhan / Disiplin Rohani - berdoa, ibadah, membaca Alkitab, puasa, berbuat amal, pertemuan rohani, dsb).

John Wesley melatih setiap anggota untuk mandiri. Ia membuat daftar yang terdiri dari 22 pertanyaan dan meminta setiap anggota untuk melakukan 'examen', (memeriksa kehidupan rohani) setiap hari. Supervisi dan coaching diberikan dengan sistematis. Setiap pertemuan ketua Class Meeting harus mengecek kehidupan rohani anggotanya, berdasarkan Three Simpe Rules. Tujuan daripada disiplin ini adalah untuk membantu para anggota Methodist mengejar kekudusan hidup supaya mereka semakin bertumbuh mendekati Kesempurnaan Kristen. Kesempurnaan Kristen atau kekudusan hidup bagi Wesley adalah hidup yang dipenuhi oleh kasih Tuhan, yang memampukan seseorang mengasihi Tuhan dengan segenap hati, segenap jiwa, segenap akal budi dan segenap kekuatan serta mengasihi sesama seperti diri sendiri (Markus 12:30-31).

Bertolak dari prinsip kasih ini, Wesley menekankan kehidupan komunitas dan pelayanan terhadap masyarakat, negara dan dunia. "Tidak ada yang namanya kekudusan pribadi tetapi kekudusan sosial." Kalimat ini pertama-tama ditujukan kepada para anggota Class Meeting untuk tidak menjadikan kekudusan hidup sebagai masalah pribadi, tetapi kekudusan harus diupayakan bersama dalam kehidupan komunitas melalui Kelas-kelas. Kedua, kekudusan bukan juga sekedar pertumbuhan rohani bagi orang Methodist tetapi untuk mentransformasi bangsa dan menyebarkan kekudusan alkitabiah di seluruh negeri. ${ }^{\text {xiv }}$ Class Meeting menjadi tempat pembentukan karakter dan pembangunan SDM yang dipersiapkan untuk mereformasi gereja dan mentransformasi bangsa.

\section{John Wesley dalam Kehidupan Sosial, Politik dan Ekonomi di Inggris}

John Wesley adalah seorang yang sangat disiplin. Ia melayani dengan menjadi model:

\section{Kepedulian Terhadap Mereka yang Miskin}

Wesley melihat keterkaitan antara menolong orang miskin dengan kekudusan Kristiani. Pelayanan kepada kaum miskin adalah sarana anugerah dimana Tuhan melakukan karya kudusNya melalui kita. Menolong orang miskin bukan sekedar memberi sedekah atau berbuat amal, tetapi merupakan cara Tuhan untuk membentuk kita mencapai kekudusan. Kepedulian ini muncul ketika ia masih menjabat sebagai dosen di Lincoln College di Oxford dan menjadi prinsip hidupnya.

"Ia baru saja membeli beberapa buah lukisan untuk menghias kamarnya ketika seorang pembantu mengetuk pintunya. Hari yang sangat dingin di musim salju. Ia memperhatikan bahwa gadis pembantu itu hanya memiliki sehelai kain linen yang tipis untuk melindungi dirinya dari udara dingin. Ia segera mengambil uang dari sakunya untuk diberikan kepada sang pembantu untuk membeli mantel. Tetapi ia mendapatkan uangnya tidak cukup. Ia segera sadar bahwa ia tidak menyenangkan Tuhan dengan caranya membelanjakan uangnya. Ia bertanya pada dirinya sendiri, Apakah Tuhan akan berkata, "Bagus, hambaKu yang baik dan setia"? Engkau sudah menghiasi dinding rumahmu 
dengan uang yang sebetulnya dapat menolong makhluk yang kasihan ini dari kedinginan! Oh keadilan! Oh belas kasihan! Tidakkah lukisan-lukisan ini darah dari gadis malang ini?"xv

Sejak hari itu, John Wesley memutuskan untuk hidup sederhana dan memberikan semua uangnya untuk menolong orang yang lebih membutuhkan. Selama hidupnya ia memiliki penghasilan lebih dari 30.000 GBP (kira-kira 4.485.688,12 GBP untuk tahun 2019) hampir semua diberikan kepada orang miskin dan pelayanan misi. Ketika meninggal, ia hanya mememiliki beberapa koin di saku bajunya. John Wesley juga menekankan prinsip hidup sederhana ini dalam kerohanian Methodist dan selalu berusaha memberdayakan orang miskin. Mereka yang kuat dan kaya menuduh bahwa kaum miskin menjadi miskin karena tidak berusaha. Wesley menyangkal dan mengecam tuduhan mereka. Melalui Paguyuban-Paguyuban dan Kelas-kelas Methodist mereka belajar ketrampilan berorganisasi, mandiri dan berpikir kritis. Tujuannya supaya mereka menjadi agen perubahan di dalam masyarakat.

\section{Kepedulian pada Perekonomian Bangsa}

Larangan untuk tidak minum-minuman beralkohol bukan sekedar alasan moral, tetapi sebagai respon Wesley terhadap situasi ekonomi waktu itu. Separuh dari hasil panen gandum di Inggris digunakan untuk membuat minuman beralkohol. Akibatnya harga gandum, bahan untuk membuat roti menjadi mahal dan tidak terjangkau oleh masyarakat miskin. Inflasi merajalela. Harga daging babi, ayam, dan telur sangat mahal dimonopoli para tuan tanah. Harga daging menjadi mahal karena para peternak lebih suka beternak kuda untuk diekspor ke Prancis untuk dijadikan sebagai kuda penarik sado para bangsawan. Untuk mengatasi masalah ini, Wesley meminta pemerintah melakukan intervensi, menciptakan lapangan pekerjaan, dan melarang pembuatan minuman beralkohol, menurunkan permintaan kuda dan menaikkan pajak tambahan terhadap sado kuda milik para bangsawan dan mengenakan pajak sebesar 10 GBP untuk setiap kuda yang diekspor ke Prancis. ${ }^{\text {xvi }}$

\section{Peduli dengan Perbudakan}

Tahun 1774, Wesley mengecam perbudakan melalui tulisannya, Thoughts Upon Slavery. Ia juga berulang kali mengecam langsung perbudakan dan menyebut perbudakan sebagai "kekejian yang paling keji." Selain John Newton, John Wesley juga ikut mempengaruhi kerohanian dan mendukung Willam Wilberforce untuk menghapus perbudakan di Inggris. Enam hari sebelum meninggal, pada tanggal 24 Pebruari 1791, Wesley menulis kepada William Wilberforce;

... Go on, in the name of God and in the power of His might, till even American slavery (the vilest that ever saw the sun) shall vanish away before it ... (Letter to William Wilberforce, 24 February, 1791, Letters (Telford) 8:26

... teruslah berjuang dengan nama Tuhan dan kuasaNya, hingga bahkan perbudakan di Amerika (yang paling kejam) dihapuskan ...

\section{Kontribusi dalam Pendidikan}

Wesley memberikan perhatian yang besar terhadap pendidikan. Di tahun-tahun terakhir hidupnya, Wesley lebih banyak menulis tentang pendidikan. Pemahamannya terhadap konsep pemulihan gambar Allah membuat John Wesley sangat percaya pengenalan akan Tuhan dan firmanNya akan membuat kita (anak-anak dan dewasa) mampu berpikir rasional sehingga mampu menolak pikiran-pikiran irrasional yang menuntun pada kebiasaan-kebiasaan dosa.

Prinsip-prinsip yang diterapkan John Wesley dalam pendidikan: 
1. Keseimbangan antara Iman dan Pengetahuan (Knowledge and Piety) yang menjadi landasan bagi sekolah-sekolah Methodist saat ini, meskipun pada pelaksanaannya tidak selalu seimbang. Melihat kemiskinan dan kualitas hidup rakyat Inggris, Wesley mendirikan sekolah Kingswood pada tahun 1748. Tujuannya adalah untuk mempersiapkan pemimpin Methodist yang cakap dan beriman. Abad 18 adalah bagian dari Mazhab Pencerahan. Para era ini cendekiawan mulai memisahkan antara iman dan ilmu pengetahuan. Namun Wesley tetap menekankan pendidikan iman dan pengenalan pribadi terhadap Kristus.

2. Karakter yang mampu mengendalikan diri sendiri. Prinsip ini sangat dipengaruhi oleh didikan ibunya, Susanah. Wesley mengajarkan: "Begitu kita melihat ada perilaku buruk yang muncul harus segera dikoreksi. Dimulai dengan pendekatan yang bersahabat dan lembut, tetapi perlu diterapkan ketegasan jika cara halus tidak berlaku." xvii

Wesley sering meminta murid-murid di Kingswood untuk bertanya pada diri mereka sendiri apakah mereka rendah hati dan dapat diajar atau mereka keras kepala dan hanya mengikuti keinginan sendiri. Ia meminta para guru memperhatikan kelakukan anak-anak di luar kelas, khususnya bagaimana mereka berinteraksi dengan orang lain jangan sampai para murid bersikap kasar, berperilaku buruk dan saling mempengaruhi dalam hal-hal yang buruk.

3. Karakter yang mampu berpikir kritis dan berhikmat. Wesley mengajarkan orang Methodist untuk berpikir dan merefleksikann iman mereka. Tujuannya adalah supaya mereka cermat dan kritis dengan diri sendiri untuk mencapai Kesempurnaan Kristen. Ia juga bersikap kritis terhadap sistem pembelajaran di masa itu. Mengingatkan kepada para guru dan orang tua untuk membantu anak-anak untuk berpikir dan bertumbuh dalam hikmat.

Perhatikan kebiasan yang buruk yang membuat anak-anak hanya membeo ... Upayakan sedaya mungkin supaya mereka memahami setiap kalimat yang mereka baca . . . dan teruslah bertanya kepada mereka pada setiap poin.... Dengan demikian mereka akan belajar berpikir ketika membaca: mereka akan bertumbuh lebih berhikmat dan lebih bijak setiap hari. "xviii

4. Membentuk pola hidup yang sederhana. Hidup sederhana sangat berkaitan dengan sikap Wesley terhadap orang miskin. Bagi Wesley, sederhana merupakan bagian dari kerohanian. Ia mengingatkan para orang tua untuk tidak memanjakan anak-anak dengan kemewahan sebaliknya menanamkan hidup sederhana sejak disi; supaya anak-anak memiliki pandangan yang benar tentang uang dan materi, mampu membedakan antara kebutuhan dan keinginan. Kekayaan tidak dapat memberikan kebahagiaan. ${ }^{\text {xix }}$

5. Etika kerja yang baik dan spirit untuk melayani masyarakat. John Wesley menantang murid-murid di Kingswood dan orang-orang Methodist untuk selalu tekun dan menggunakan karunia serta talenta yang diberikan oleh Tuhan. "Gunakan setiap talenta yang dipinjamkan Tuhan kepadamu, jangan biarkan ia menganggur." Seorang Methodist yang mengasihi Tuhan akan penuh dengan kasih kepada sesama, kasih yang universal kepada orang yang dikenal maupun tidak, bahkan musuh sekalipun. Mengasihi orang yang dekat maupun yang jauh, yang baik maupun yang jauh tanpa pandang bulu. ${ }^{\mathrm{xx}}$

6. Pembelajaran seumur hidup (life-long learning). Kepada para pengkhotbah Methodist ia mengatakan, "Tidak mungkin seseorang dapat bertumbuh dalam anugerah jika ia tidak memberikan waktu untuk membaca.' xxi Wesley membuat daftar buku yang direkomendasikan, membuat perpustakaan, membeli perusahaan percetakan untuk mencetak bahan-bahan pengajaran 
dan bacaan, termasuk buku hymnal yang dirancang untuk mengajarkan dasar-dasar iman. Ketika mendirikan sekolah Kingswood, ia juga membuka kelas untuk orang dewasa. Di Paguyuban-paguyuban Methodist ia juga membuat seminar-seminar untuk pembelajaran bagi orang dewasa (adult learning). Ia membuat program belajar dan membaca dalam topik-topik moral, pastoral, dan isu-isu teologi yang muncul.

\section{KESIMPULAN: SARAN DAN REFLEKSI}

Pemerintah mencoba bersikap tenang dan optimis menghadapi globalisasi dan bonus demografi dengan memetakan tantangan dan memberikan prioritas pada pembangunan SDM-melalui pendidikan dan kesehatan. Kesehatan bisa cepat diatasi dengan sistem yang tepat sasaran dan tepat guna. Tantangan lebih besar ada pada penataan bidang pendidikan.

Disrupsi yang besar dan terus berubah, selain pembangunan infrastruktur teknologi seperti tol langit, guru-guru yang umumnya dari Boomers, Generasi X dan sebagian Millennial perlu menyesuaikan diri (update and upgrade) dengan sistem Internet of Things Revolusi dan memiliki Generational Intelligence (GQ) untuk dapat memahami dan berinteraksi dengan anak-anak Generasi Internet.

Pergumulan ini tentu juga menjadi pergumulan gereja. Banyak gereja yang sibuk (bahkan panik) menghadapi arus globalisasi dan disrupsi. Gereja arus utama yang lebih tradisional bingung melihat anak-anak- muda mulai meninggalkan gereja. Sebagian pemimpin mulai memperhatikan penampilan fisik gereja dan berusaha menjadi relevan dengan melakukan investasi dalam musik dan media. Sebagian mulai membangun platform untuk pelayanan digital.

Gereja tidak bisa hanya sibuk berbenah diri secara fisik dan melupakan panggilannya untuk menghadirkan Kerajaan Allah di tengah-tengah arus globalisasi. Misi gereja bukan hanya bersifat centripetal, seperti pada Perjanjian Lama, dimana Yerusalem dan Bait Allah menjadi pusat kehidupan rohani. Menunggu orang-orang untuk datang ke gereja. Di Perjanjian Baru, sesudah Pentakosta, strategi misi menjadi centrifugal. Dengan pimpinan Roh Kudus, para rasul menyebar untuk menghadirkan Kristus dan Kerajaan Allah di tengah-tengah masyarakat. Gereja dipanggil dan diutus untuk menjadi garam dan terang (Matius 5:13-16). Untuk itu gereja harus hadir di tengah-tengah kehidupan bangsa. Garam untuk menawarkan ajaran yang tidak sesuai dengan nilai-nilai gereja. Terang memberikan panduan di tengah kegamangan menghadapi arus globalisasi dan Revolusi Industri Jilid 4, ikut berperan aktif dalam pembangunan SDM yang unggul.

Pekerjaan yang bersifat pengulangan dan menghafal akan terus tergerus oleh perkembangan teknologi otomatisasi dan kecerdasan buatan (artificial intelligence). Namun kemampuan untuk berempati, kreativitas, dan berpikir kritis tidak bisa digantikan oleh mesin. Ruang untuk peran serta gereja yang sesungguhnya adalah kembali kepada "panggilan gereja" - membangun SDM yang bukan hanya memiliki kompetensi dan kapapabilitas, tetapi memiliki iman, akhlak dan budi pekerti. Membangun insan-insan yang dipulihkan, yang terus bertumbuh semakin mendekati desain yang semula, yaitu gambar Allah sendiri.

Empat hal yang dapat dicontoh dari kepemimpinan John Wesley dalam menyebarkan kekudusan alkitabiah sampai ke seluruh negeri: Pertama, John Wesley bukan berperan sebagai pendeta centripetal yang menunggu orang-orang datang kepadanya, tetapi misinya bersifat centrifugal, ia meresponi kebutuhan-kebutuhan orang Inggris dan pergi ke tempat publik dan menghadirkan Kerajaan Allah kepada mereka. 
Kedua, John Wesley membuat terobosan dalam pembentukan iman dan pembangunan SDM di Inggris melalui: examen pribadi setiap hari, pertemuan rohani Band dan Class, Pengajaran di Society, dan Konferensi untuk pembekalan para Pengkhotbah Awam. Pengajaran Wesleyan bukan sekedar informasi, tetapi formasi pembentukan iman dan karakter yang interaktif dan terpantau dengan baik. Melalui Class Meeting, mereka saling memperhatikan dan saling mendukung dalam pertumbuhan kasih menuju kekudusan hidup. Class Meeting ini juga berperan sebagai agen perubahan. Secara teratur Class-Class Meeting ini melakukan pelayanan sosial untuk menjangkau masyarakat di mana mereka.

Ketiga, di era digital ini ketika makin banyak orang, khususnya generasi muda yang menghabiskan waktu di internet, perjumpaan secara personal dan persahabatan yang tulus semakin dibutuhkan. John Wesley dengan metode Class Meeting dan Band menjadi komunitas yang memungkinkan orang-orang untuk berinteraksi secara pribadi dan memupuk persahabatan dan saling mendukung dalam pertumbuhan.

Keempat, berperan aktif sebagai suara nurani bangsa dan secara intensional memuridkan para pemimpin bangsa, seperti para Wilberforce era ini untuk menyikapi dan terlibat mencari jalan keluar bagi berbagai permasalahan bangsa dan negara. Seperti masalah korupsi dan ancaman terhadap ideologi bangsa khususnya terhadap generasi muda. Gereja tidak bisa hanya playing victim tetapi aktif terlibat dan mendukung pemerintah dalam upaya ini untuk menciptakan keharmonisan hidup berbangsa dan bernegara.

\section{Endnotes:}

i Pidato Kenegaraan Presiden Joko Widodo, 16 Agustus 2019, Sidang Bersama DPD dan DPR

ii Harding, F.A.J., The Social Impact of the Evangelical Revival: The Brief Account of the Social Influences of the Teaching of John Wesley and His Followers. Historical Magazine of the Protestant Episcopal Church Vol. 15, No. 4 (DECEMBER, 1946), pp. 256-284

iii Indonesia Human Capital Knowledge Series. The World Bank: 26 September 2019

iv Global Competitiveness Report 2019: How to end a lost decade of productivity growth. World Economic Forum

v BONUS DEMOGRAFI 2030-2040: STRATEGI INDONESIA TERKAIT KETENAGAKERJAAN DAN PENDIDIKAN. Kementerian PPN/Bappenas, Konferensi Pers 22 Mei 2017.

vi Kasali, Rhenald. Disruption. Jakarta: Gramedia, 2017

vii Pidato Presiden Jokowi, 16 Agustus 2019

viii Welcoming Faith in the Fourth Industrial Revolution. George Town University: Berkeley Center for Religion, Peace, and World Affairs. 21 Juni 2016. Diakses 14 Oktober 2019

ix Laporan Survey 2018: Penetrasi \& Profil Perilaku Pengguna Internet Indonesia. Asosiasi Penyelenggara Jasa Internet Indonesia

${ }^{x}$ Vieira, Josh. Understanding Multigenerational Dynamics in the Marketplace. Coaching Workshop di STT Bandung, 19 Oktober 2019. 
xi Teknologi mempermudah kolaborasi lintas negara dan lintas budaya, sehingga muncul situs seperti Wikipedia yang memberikan kesempatan kepada siapa saja untuk berkontribusi.

xii Steve, Robertson. Generation Z Characteristics \& Traits That Explain The Way They Learn. Di blog Julian Kinsky Camp \& Program. 25 July 2018. Diakses 29 Oktober 2019.

Tracy Francis and Fernanda Hoefel. The influence of Gen Z-the first generation of true digital natives - is expanding. Di situ McKinsey \& Company: Nop 2018.

xiii The General Rules of the Methodist Church: The Nature, Design, and General Rules of Our United Societies. The Book of Discipline of The United Methodist Church-2016. Di unduh dari umc.org.

xiv John Wesley, Khotbah "Scriptural Holiness." 1744

xv Solomon, Robert. “John Wesley and the Poor". Methodist Message.

xvi Misleading Wesley info in Wesleyan Christian Advocate. MethodistThinker.com, 7 November 2008. Diakses 30

Oktober 2019

xvii Thought on the Manner of Educating Children." Dalam The Works of the Rev. John Wesley, Volume 10m." John Wesley, New York: J\&J Harper, 1827

xviii Wesley, John "To All Parents and Schoolmasters." Dalam The Works of the Late Reverend John Wesley, A.M.: From the Latest ..., Volume 7. New York: J\&J Harper .1831. (Letter to Kingswood School)

xix Wesley, John. Khotbah "On the Education of Children.”

xx Wesley, John. "A Plain Account of Genuine Christianity.” Dalam "John Wesley" Ed. Albert Outler. New York: Oxford University, 1964. Hal. 184

Wong, Melisa, dkk. Generational Differences in Personality and Motivation: Do They Exist and What Are the Implications for the Workplace? Dalam Journal of Managerial Psychology 23(8):878-890. Nov 2008

xxi Letter to George Holder 8 Nov 1790

\section{Referensi Tambahan}

5 ways of understanding the Fourth Industrial Revolution. Nicholas Davis, Head of Society and Innovation, Member of the Executive Committee, World Economic Forum. 16 Nopember 2015

Schwab, Klaus. Revolusi Industri Keempat. Jakarta: Gramedia, 2019 


\section{DAFTAR PUSTAKA}

Afandi, Thohir. "Bonus Demografi 2030-2040: Strategi Indonesia Terkait Ketenagakerjaan Dan Pendidikan." Kementerian Perencanaan Pembangunan Nasional, 2017, 1-2.

APJII. "Penetrasi \& Profil Perilaku Pengguna Internet Indonesia Tahun 2018.” Apjii, 2019, 51. www.apjii.or.id.

Harding, F. A. J. The social impact of the evangelical revival : a brief account of the social influences of the teaching of John Wesley and his followers / by F.A.J. Harding Epworth Press London 1947

“Indonesia Human Capital Knowledge Series.” Accessed October 30, 2019.

https://www.worldbank.org/en/country/indonesia/brief/indonesia-human-capital.

Kasali, Rhenald. Disruption. Jakarta: Gramedia, 2017

Later to George Holder dated 8 Nov. 1790 in Telford (1931) The Letters of the Rev. John Wesley Vol. 8 p 247

liputan6.com. "Ini Pidato Lengkap Jokowi Di Depan Sidang Bersama DPD Dan DPR RI - News Liputan6.Com." liputan6.com. Accessed October 30, 2019.

https://www.liputan6.com/news/read/4039251/ini-pidato-lengkap-jokowi-di-depan-sidang-bersama-dpd-d an-dpr-ri.

"Misleading Wesley Info in Wesleyan Christian Advocate | MethodistThinker.Com." Accessed October 30, 2019.

https://methodistthinker.com/2008/11/07/misleading-wesley-excerpt-in-wesleyan-christian-advocate/

Schwab, Klaus. Insight Report - The Global Competitiveness Report 2019 World Economic Forum, 2019.

."Welcoming Faith in the Fourth Industrial Revolution." Accessed October 14, 2019.

https://berkleycenter.georgetown.edu/responses/welcoming-faith-in-the-fourth-industrial-revolution.

Sigmon, Brian O. (Managing editor). The Book of Discipline Of the United Methodist Church. The United Methodist Publishing House, 1980.

Stave Robertson. Generation Z Characteristics \& Traits That Explain the Way They Learn. Edited by Robertson Stave. Accessed October 2, 2019. https://info.jkcp.com/blog/generation-Z-characteristics.

Thought on the Manner of Educating Children." Dalam The Works of the Rev. John Wesley, Volume 10m.” John Wesley, New York: J\&J Harper, 1827

Tracy Francis, Fernanda Hoefel. "Generation Z Characteristics and Its Implications for Companies | McKinsey.” Accessed September 27, 2018.

https:/www.mckinsey.com/industries/consumer-packaged-goods/our-insights/true-gen-generation-z-and-i $\underline{\text { ts-implications-for-companies. }}$ 
Vieira, Josh. Understanding Multigenerational Dynamics in the Marketplace. Coaching Workshop di STT Bandung, 19 Oktober 2019.

Wesley, John "To All Parents and Schoolmasters." Dalam The Works of the Late Reverend John Wesley, A.M.: From the Latest ..., Volume 7. New York: J\&J Harper .1831. (Letter to Kingswood School)

Wesley, John. "A Plain Account of Genuine Christianity" in John Wesley (ed: Albert C. Outler). New York: Oxford University Press, 1980. pp.181-196

Wesley, John. John Wesley and the Education of Children, n.d.

Wong, Melissa, Elliroma Gardiner, Whitney Lang, and Leah Coulon. "Generational Differences in Personality and Motivation: Do They Exist and What Are the Implications for the Workplace?" Journal of Managerial Psychology 23, no. 8 (2008): 878-90. https://doi.org/10.1108/02683940810904376. 